\title{
Wound infection with Vibrio harveyi following a traumatic leg amputation after a motorboat propeller injury in Mallorca, Spain: a case report and review of literature
}

\author{
Thomas Theo Brehm ${ }^{1,2^{*}}$ (D), Laura Berneking ${ }^{3}$, Holger Rohde $^{2,3}$, Martin Chistner $^{3}$, Carsten Schlickewei ${ }^{4}$,
} Meike Sena Martins ${ }^{5}$ and Stefan Schmiedel ${ }^{1,2}$

\begin{abstract}
Background: Vibrio spp. are aquatic bacteria that are ubiquitous in warm estuarine and marine environments, of which 12 species are currently known to cause infections in humans. So far, only five human infections with $V$. harveyi have been reported.

Case presentation: A 26-year old patient was transferred to our center by inter-hospital air transfer from Mallorca, Spain. Seven days before, he had suffered a complete amputation injury of his left lower leg combined with an open, multi-fragment, distal femur fracture after he had been struck by the propeller of a passing motorboat while snorkeling in the Mediterranean Sea. On admission he was febrile; laboratory studies showed markedly elevated inflammatory parameters and antibiotic treatment with ampicillin/sulbactam was initiated. Physical examination showed a tender and erythematous amputation stump, so surgical revision was performed and confirmed a putrid infection with necrosis of the subcutaneous tissue and the muscles. Tissue cultures subsequently grew $\mathrm{V}$. harveyi with a minimal inhibitory concentration (MIC) of $16 \mathrm{mg} / \mathrm{L}$ for ampicillin, and antibiotic treatment was switched to ceftriaxone and ciprofloxacin. Throughout the following days, the patient repeatedly had to undergo surgical debridement but eventually the infection could be controlled, and he was discharged.

Conclusions: We report the first human infection with $V$. harveyi acquired in Spain and the second infection acquired in the Mediterranean Sea. This case suggests that physicians and microbiologists should be aware of the possibility of wound infections caused by Vibrio spp. acquired in the ocean environment, especially during hot summer months. Since Vibrio spp. preferentially grow at water temperatures above $18^{\circ} \mathrm{C}$, global warming is responsible for an abundance of these bacteria in coastal waters. This will likely lead to a worldwide increase in reports of Vibrio-associated diseases in the future.
\end{abstract}

Keywords: Vibrio harveyi, Vibrio carchariae, Non-cholera Vibrio, Amputation injury, Motorboat propeller injury, Wound infection, Mediterranean Sea, Climate change, Global warming, Sea surface temperature

\footnotetext{
* Correspondence: thomastheobrehm@gmail.com

${ }^{1}$ Division of Infectious Diseases, I. Department of Internal Medicine, University

Medical Center Hamburg-Eppendorf, Hamburg, Germany

${ }^{2}$ German Center for Infection Research (DZIF), Partner Site

Hamburg-Lübeck-Borstel-Riems, Hamburg, Germany

Full list of author information is available at the end of the article
}

C The Author(s). 2020 Open Access This article is distributed under the terms of the Creative Commons Attribution 4.0 International License (http://creativecommons.org/licenses/by/4.0/), which permits unrestricted use, distribution, and reproduction in any medium, provided you give appropriate credit to the original author(s) and the source, provide a link to the Creative Commons license, and indicate if changes were made. The Creative Commons Public Domain Dedication waiver (http://creativecommons.org/publicdomain/zero/1.0/) applies to the data made available in this article, unless otherwise stated. 


\section{Background}

Vibrio is a genus of Gram-negative, rod-shaped bacteria that can be found in a wide variety of estuarine and marine environments. Of the $>100$ described Vibrio spp., at least 12 species are currently known to have the potential to cause human infections (Table 1 ).

The toxin-producing serogroups O1 and O139 of $V$. cholerae can cause endemic and epidemic cholera, a severe acute secretory diarrheal illness that is primarily transmitted via ingestion of contaminated food or water. Non-cholera Vibrio spp. infections are most often caused by halophilic species that thrive in saltwater. Thus, these infections are usually associated with consumption of raw or undercooked seafood or traumatic exposure to sea or brackish water and can to a variable degree cause gastroenteritis and wound infections [1-3]. $V$. harveyi (synonym $V$. carchariae) is known to be one of the causative agents of systemic fish disease as well as seafood spoilage [4, 5] and has long been considered non-pathogenic to humans [6]. However, sporadic case reports about human infections have been published in the recent years. The purpose of this study was to report the second human infection with $V$. harveyi acquired in the Mediterranean Sea in order to increase alertness in physicians and microbiologists, since the ongoing global warming will likely lead to a worldwide increase in Vibrio-associated infections.

\section{Case presentation}

During July 2018, a 26-year old, previously healthy male had been struck by the propeller of a passing motorboat

Table 1 Vibrio spp. that cause, or are associated with, human infections (modified from [1])

\begin{tabular}{|c|c|c|}
\hline \multirow[t]{2}{*}{ Species } & \multicolumn{2}{|c|}{ Occurrence in clinical specimens } \\
\hline & Intestinal & Extraintestinal \\
\hline V. alginolyticus & - & ++ \\
\hline \multicolumn{3}{|l|}{ V. cholerae } \\
\hline 01/0139 & ++++ & + \\
\hline non-01/0139 & ++ & ++ \\
\hline V. cincinnatiensis & - & + \\
\hline V. damsela & - & + \\
\hline V. fluvialis & ++ & - \\
\hline V. furnissii & ++ & - \\
\hline V. harveyi & - & + \\
\hline V. hollisae & ++ & - \\
\hline V. metschnikovii & + & + \\
\hline V. mimicus & ++ & + \\
\hline V. parahaemolyticus & ++++ & + \\
\hline V. vulnificus & + & +++ \\
\hline
\end{tabular}

The symbols,,++++++ and ++++ give the relative frequency of each organism in the specimens; - , not found while snorkeling on the shore of the Balearic island of Mallorca, Spain. He suffered complete amputation injury at the level of the proximal tibia and fibula as well as multi-fragment distal femur fracture of his left lower extremity (Fig. 1). Due to retrograde amnesia the patient was not able to provide more detailed information concerning the accident occurrence. At the local hospital, the lower leg showed extensive soft-tissue damage and had to be amputated. The open, multi-fragment distal femur fracture was reduced and stabilized with an external fixator. Postoperatively, the patient was transferred to an intensive care unit. Seven days after the injury, on August 02, 2018 the patient was presented to our center by inter-hospital air transfer. On admission he was febrile with a temperature of $38.5^{\circ} \mathrm{C}$. Laboratory studies revealed a normal white blood cell count of $7.3 \times 10^{9} / 1$ (reference $3.8-11.0 \times 10^{9} / \mathrm{l}$ ), anemia with hemoglobin level of $10.0 \mathrm{~g} / \mathrm{dl}$ (reference $14.0-17.5 \mathrm{~g} / \mathrm{dl}$ ) and elevated



Fig. 1 Anterior posterior X-ray of the left lower extremity. a After transport of the patient from Spain to our hospital, with lower leg stump and external fixator, after traumatic amputation of the lower leg and open, multi-fragmentary, distal femoral fracture (day 1). b After definitive surgery, with a closed, infection-free amputation stump and after open reduction and stabilization of the multi-fragment distal femur fracture with an angular stable plate osteosynthesis (day 20) 
C-reactive protein of $253 \mathrm{mg} / \mathrm{l}$ (reference $<5 \mathrm{mg} / \mathrm{l}$ ). Chest radiograph and urine analysis showed no abnormalities and four sets of blood culture showed no growth of bacteria. Initially the amputation stump and the wound on the thigh showed no clinical signs of infection. Blood cultures were collected before empiric antimicrobial therapy was initiated with ampicillin/sulbactam. Two days later clinical examination revealed a warm, tender and erythematous amputation stump; hence a wound infection was suspected. On August 04, 2018 surgical revision revealed a putrid infection of the amputation stump with necrosis of the subcutaneous tissue and the muscles. Due to the advanced infection, a rigorous and aggressive debridement of skin, subcutaneous tissue, fascia, muscle and bone was performed. The amputation stump was temporarily closed with a vacuum assisted closure-therapy. The external fixator was removed, and the pin sites and the wound were cut out. Subsequently, the multi-fragmented distal femur fracture was reduced and stabilized with a new external fixator. During the surgery several microbiological samples were submitted for microbiologic examination. Culture incubation of a wound swab readily grew bacteria that were identified as $V$. harveyi by matrix-assisted laser desorption ionization/time-of-flight mass spectrometry fingerprinting using a biotyper instrument (Bruker Daltonics, Bremen, Germany). The wound culture was monomicrobial without growth of any other pathogens. Minimal inhibitory concentrations (MICs) were determined by gradient diffusion (Etest ${ }^{\circ}$, bioMérieux, Marcy-l'Étoile, France; MIC Test Strip, Liofilchem, Roseto degli Abruzzi, Italy). According to non-species related EUCAST breakpoints, the isolate was classified as susceptible to meropenem (MIC $0.004 \mathrm{mg} / \mathrm{mL}$ ), ciprofloxacin $(0.125 \mathrm{mg} / \mathrm{mL})$ and ceftriaxone $(0.032 \mathrm{mg} / \mathrm{mL})$ and resistant to ampicillin $(32 \mathrm{mg} / \mathrm{mL})$ (Table 2$)$.

Thus, antibiotic treatment was transitioned to ceftriaxone and ciprofloxacin. Throughout the following days, the patient repeatedly had to undergo surgical debridement, but the infection could eventually be controlled. Sixteen days after the first surgical revision the amputation stump could be closed, and the multi-fragment distal femur fracture was stabilized with a 9-hole $\mathrm{NCB}$ distal femur plate (Fig. 1b). On September 04, 2018, antibiotic treatment was stopped, and the patient was discharged to a rehabilitation facility.

Whole genome sequencing of the isolate was retrospectively performed with an Illumina NextSeq instrument using $2 \times 150 \mathrm{bp}$ paired-end chemistry (SRA accession PRJNA576306). Reads were assembled with shovill 1.0.4 (https:/github.com/tseemann/shovill) and spades 3.13.1 [7] into a draft genome with 107 contigs larger than 200 bp (N50 409272, L50 4) and a total length of 6.1 million bp. An average nucleotide identity of 98.6 to 98.8 with
Table 2 Antimicrobial susceptibility of Vibrio harveyi with interpretation according to non-species related EUCAST breakpoints

\begin{tabular}{|c|c|c|}
\hline Antimicrobial agent & $\mathrm{MIC}(\mu \mathrm{g} / \mathrm{ml})$ & Interpretation \\
\hline Amikacin & 8 & \\
\hline Amoxicillin & 16 & $\mathrm{R}$ \\
\hline Ampicillin & 16 & $\mathrm{R}$ \\
\hline Azithromycin & 2 & \\
\hline Aztreonam & 2 & $\mathrm{~S}$ \\
\hline Ciprofloxacin & 0.125 & $\mathrm{~S}$ \\
\hline Ceftriaxon & 0.125 & $S$ \\
\hline Erythromycin & 4 & \\
\hline Gentamicin & 1 & \\
\hline Imipenem & 0.125 & $S$ \\
\hline Meropenem & 0.064 & $\mathrm{~S}$ \\
\hline Moxifloxacin & 0.25 & \\
\hline Penicillin & $>32$ & $\mathrm{R}$ \\
\hline Piperacillin/Tazobactam & 0.125 & $S$ \\
\hline TMP/SMX & 0.032 & \\
\hline Doxycycline & 0.25 & \\
\hline Tobramycin & 2 & \\
\hline Tetracyclin & 0.25 & \\
\hline Streptomycin & 16 & \\
\hline
\end{tabular}

I intermediate, MIC minimum inhibitory concentration, $R$ resistant, $S$ susceptible, TMP/SMX trimethoprim/sulfamethoxazole

genomes of $V$. harveyi strains 345, ATCC 33843, CAIM 1792, NCTC 12970, VHJR4 and QT520 confirmed the species identification [8]. RAST-annotation [9] and analysis with the SEED-viewer [10] showed a nearly identical profile of the investigated $V$. harveyi strains in the virulence, disease and defense subsystem category. An additional blast-search against the virulence factor database [11] did not reveal additional atypical virulence factors (e. g. toxins) in our isolate. In agreement with phenotypic testing (Table 2) resistance gene profiling identified a class A beta-lactamase showing 100\% amino acid identity to the beta-lactamase of $V$. harveyi CAIM 1792 (GenBank ${ }^{\circ}$ accession number EMR34292.1).

\section{Discussion and conclusion}

So far, only five human infections caused by $V$. harveyi have been reported. The first report described a wound infection acquired by an 11-year-old girl after being attacked by a shark while wading in knee-deep water off the South Carolina coast [12]. The second case was an episode of catheter-related bacteremia in a 9-year old British oncologic patient with a central line after returning from a holiday in Perpignan, France, where he had swum in the Mediterranean Sea [13]. Both a 64-year-old and a 75-year-old man acquired mixed wound infections 
with Photobacterium damselae and $V$. harveyi in Australia after experiencing a laceration injury after falling from a catamaran and after fishing without recalling any trauma respectively $[14,15]$. Another wound infection with $V$. harveyi occurred in a 49-year old immunosuppressed Spanish traveler in the Dominican Republic after experiencing trauma from striking a bus step and subsequently swimming in the sea [16].

In our patient, culture incubation of a wound swab grew $V$. harveyi on August 04, 7 days after the initial injury and admission to the local hospital. The culture was monomicrobial without growth of any other pathogens. It is beyond our knowledge whether tissue cultures were performed prior to transferal to our hospital. However, a wound contamination is highly unlikely given that $V$. harveyi is a halophilic bacterium that only grows in saltor brackish water.

Not all strains of $V$. harveyi are virulent. However, despite the role of the bacteria as a pathogen for both a wide range of both marine animals and humans, the pathogenicity mechanisms have not been fully understood yet [17]. The range of virulence determinants include among others the ability to attach and form biofilms, lipopolysaccharide, proteases, hemolysins, bacteriophage interaction and quorum sensing. Virulence factors of other Vibrio spp. like $V$. vulnificus also include an anti-phagocytic polysaccharide capsule, a variety of extracellular toxins and iron utilization [18]. All Vibrio spp. preferentially grow at water temperatures above $18^{\circ} \mathrm{C}$ and for $V$. harveyi the optimal temperature for reproduction is $26^{\circ} \mathrm{C}[19,20]$. Therefore, most cases of Vibrio infections have usually been reported in tropical or subtropical regions [21]. However, climate change is responsible for a rapidly warming marine environment globally and especially in European seas [22]. During the last decades the warming trend of the Mediterranean reached $0.36{ }^{\circ} \mathrm{C}$ per decade, exceeding the global ocean average of $0.15^{\circ} \mathrm{C}$ per decade [23, 24]. The mean sea surface temperature (SST) off the south coast of the Balearic island of Mallorca, Spain during the summer months (June, July and August) has even increased by $0.51^{\circ} \mathrm{C}$ per decade since 1980 (Fig. 2, Additional file 1). During the 1980s the SST in the Mediterranean amounted more than $26^{\circ} \mathrm{C}$ only on 8 days per year on average. In contrast, during the recent 8 years an SST of more than $26^{\circ} \mathrm{C}$ was measured on an average of 35 days per year (Fig. 3). Thus, the number of days on which the SST is suitable for growth of Vibrio spp. in general and $V$. harveyi in particular $\left(\mathrm{SST}>26^{\circ} \mathrm{C}\right)$ has steadily increased. The warming trend for the Mediterranean Sea will not decelerate for the next 100 years and the SST projected by these climate studies for the end of the current century is controlled mainly by emission variations rather than seasonal or regional variations [25]. This is likely to lead to a further increase in the abundance of those bacteria in the surface water and

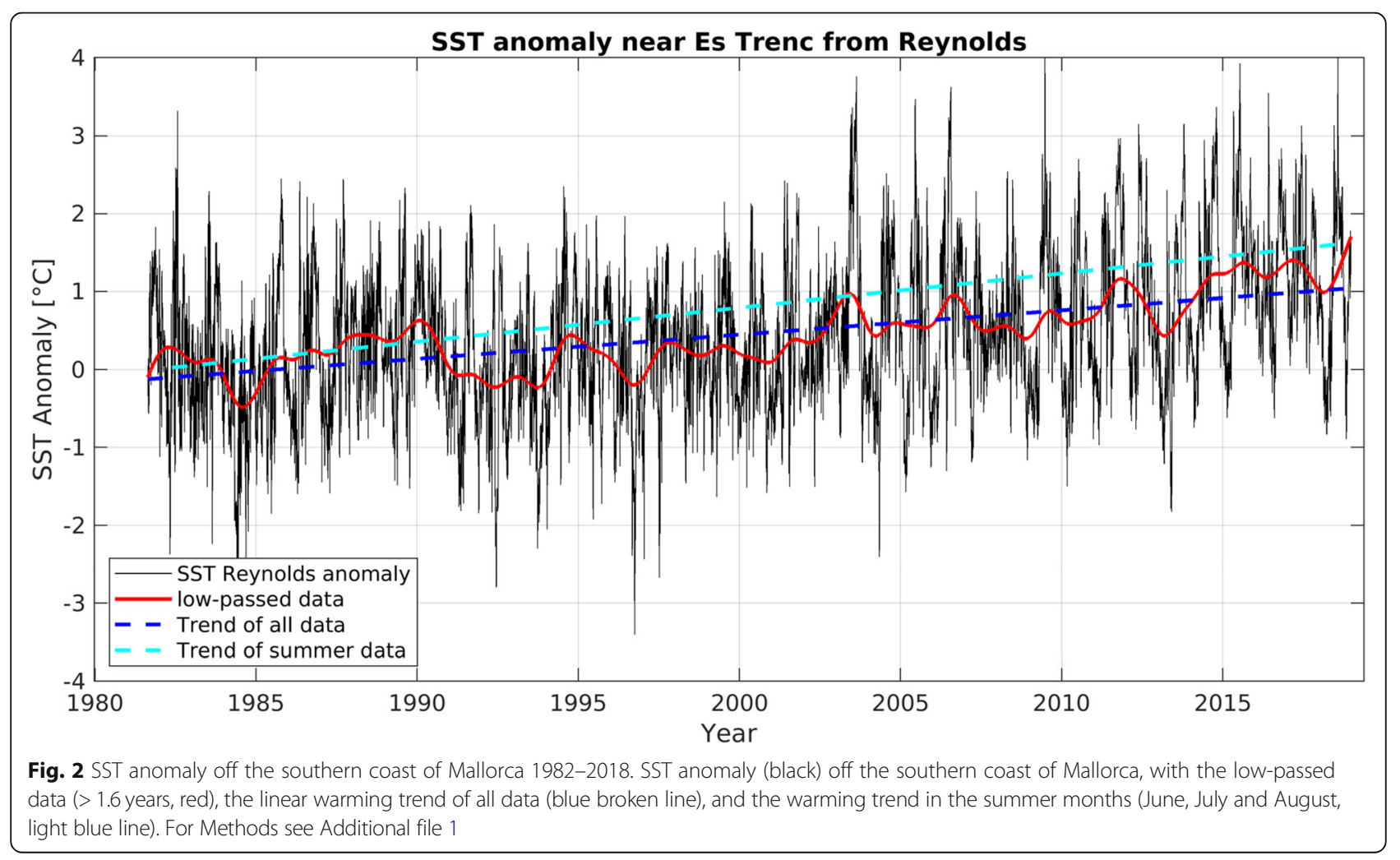




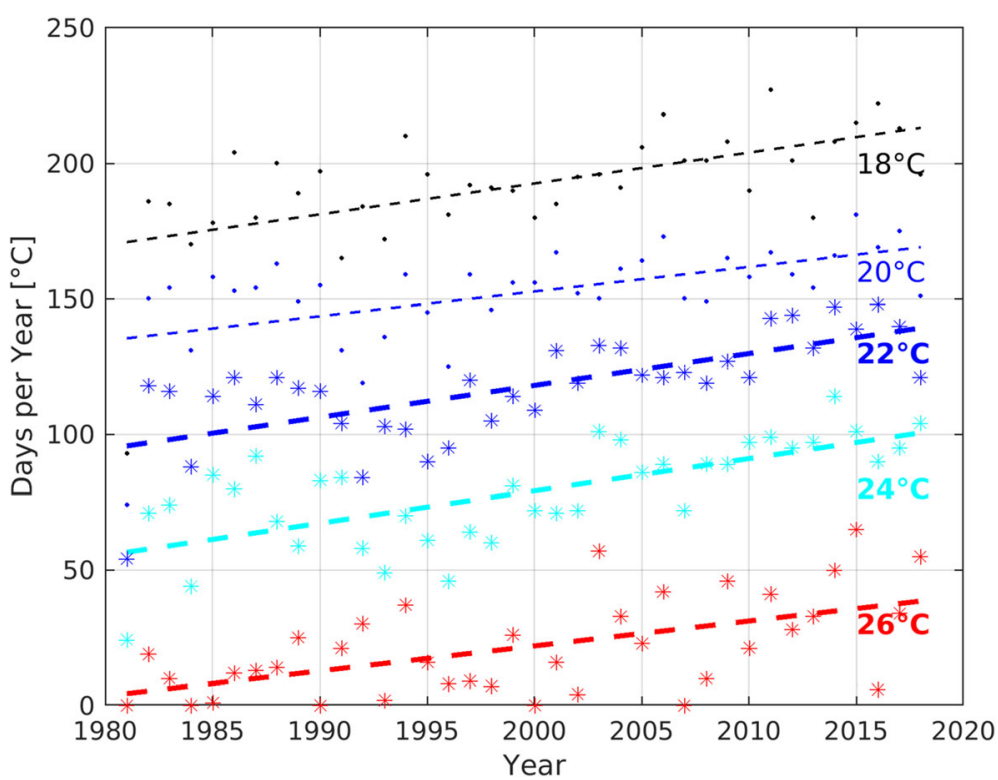

Fig. 3 Absolute SST off the southern coast of Mallorca 1982-2018. Number of days with Reynolds SST off the southern coast of Mallorca exceeding $18^{\circ} \mathrm{C}$ (black), $20^{\circ} \mathrm{C}$ (blue, thin), $22^{\circ} \mathrm{C}$ (blue), $24^{\circ} \mathrm{C}$ (cyan) and $26^{\circ} \mathrm{C}$ (red). The symbols denote the number of days per year, whereas the broken line shows the respective trend from 1982 to end 2018. For Methods see Additional file 1

subsequently to an increase of human infections. However, while cholera infection due to $V$. cholerae (O1, O139) is a reportable disease in all European countries, infections with other Vibrio spp. are not reportable in all countries. This lack of mandatory notification systems prevents accurate estimates for infections with Vibrio spp. in Europe and a high number of unreported infections must be assumed [26]. In the Baltic Sea, where the warming trend is even $0.6{ }^{\circ} \mathrm{C}$ per decade, this increase in SST already has been linked to an increase of domestically acquired human infections with Vibrio spp. in several littoral states, most likely also since national quality of monitoring in littoral states is higher than in Mediterranean countries [27-29]. Outbreaks with high numbers of reported cases have been reported during heat waves, when recreational exposure to water, which appears to be responsible for a sizeable proportion of reported infections, also substantially increases [27].

Another factor that has been identified to play a role in controlling abundance of Vibrio spp. is sea salinity. Each Vibrio spp. is associated with a distinct, speciesspecific salinity range [30]. While $V$. parahaemolyticus (5-30 psu [practical salinity units]) [31], V. vulnificus (8-16 psu) [32] and $V$. cholerae (0-20 psu) [30] most commonly thrive at relatively low salinity, $V$. harveyi preferentially grows at relatively higher salinities of 30 to 40 psu [33]. The Mediterranean Sea has a salinity of 38 psu, which is the highest of all European seas and represents optimal growth conditions for $V$. harveyi.

While we report only the second human infection with $V$. harveyi acquired in the Mediterranean Sea, this species has been reported to be responsible for mass mortality events in benthic invertebrates in the Mediterranean Sea and to remain a major threat to the survival of those animals due to potential climate change related disease outbreaks [34].

In light of the high fatality rates associated with wound infections caused by Vibrio spp., early and aggressive antimicrobial therapy is essential. Clinical data from retrospective studies on patients with wound infections or septicemia by $V$. vulnificus support a combination antibiotic therapy with a third-generation cephalosporin plus a tetracycline or fluoroquinolone. This regimen can be employed as initial calculated therapy if an infection with Vibrio spp. is suspected. However, during the last decades antimicrobial resistance against all available antibiotics including carbapenems has been shown in different Vibrio spp. and multidrug resistant strains have become a significant healthcare concern [35-38].

In conclusion, physicians and microbiologists should be aware that Vibrio spp. are emerging pathogens and due to ongoing global warming, will likely lead to a worldwide increase in reports of Vibrio-associated wound infections and gastrointestinal infections acquired also in European seas including the Mediterranean.

\section{Supplementary information}

Supplementary information accompanies this paper at https://doi.org/10 1186/s12879-020-4789-2.

Additional file 1. Methods for Figure 2 and Figure 3.

\section{Abbreviations}

MIC: Minimal inhibitory concentration; psu: Practical salinity units; SST: Sea surface temperature 


\section{Acknowledgements}

Not applicable.

\section{Authors' contributions}

All authors have read and approved the manuscript. TTB conceived and designed the study, analyzed the clinical data, drafted and edited the manuscript. LB analyzed and interpreted microbiological data and edited the manuscript. HR analyzed and interpreted microbiological data and edited the manuscript. MC analyzed and interpreted microbiological data and edited the manuscript. CS interpreted clinical data and edited the manuscript. MSM performed climatological analyses, created Figs. 2 and 3 and edited the manuscript, SS conceived and designed the study and was a major contributor in writing the manuscript.

\section{Funding}

Not applicable.

\section{Availability of data and materials}

Data sharing is not applicable to this article as no datasets were generated or analyzed during the current study.

\section{Ethics approval and consent to participate}

Not applicable.

\section{Consent for publication}

Written consent to publish this information was obtained from the patient. A copy of the written consent form is available for the journal, if requested.

\section{Competing interests}

The authors declare that they have no competing interests.

\section{Author details}

'Division of Infectious Diseases, I. Department of Internal Medicine, University Medical Center Hamburg-Eppendorf, Hamburg, Germany. ${ }^{2}$ German Center for Infection Research (DZIF), Partner Site Hamburg-Lübeck-Borstel-Riems, Hamburg, Germany. ${ }^{3}$ Institute of Medical Microbiology, Virology and Hygiene, University Medical Center Hamburg-Eppendorf, Hamburg, Germany. ${ }^{4}$ Department of Trauma, Hand, and Reconstructive Surgery, University Medical Center Hamburg-Eppendorf, Hamburg, Germany. ${ }^{5}$ Institute of Oceanography, University of Hamburg, Hamburg, Germany.

\section{Received: 14 June 2019 Accepted: 14 January 2020}

\section{Published online: 04 February 2020}

\section{References}

1. Dalsgaard A. The occurrence of human pathogenic Vibrio spp. and Salmonella in aquaculture. Int J Food Sci Technol. 1998;33:127-38.

2. Dechet AM, Yu PA, Koram N, Painter J. Nonfoodborne Vibrio infections: an important cause of morbidity and mortality in the United States, 1997-2006. Clin Infect Dis. 2008:46(7):970-6.

3. Altekruse SF, Bishop RD, Baldy LM, Thompson SG, Wilson SA, Ray BJ, et al. Vibrio gastroenteritis in the US Gulf of Mexico region: the role of raw oysters. Epidemiol Infect. 2000;124(3):489-95.

4. Zhang $X-H$, Austin B. Pathogenicity of Vibrio harveyi to salmonids. J Fish Dis. 2000:23:93-102.

5. Pasharawipas T, Thaikua S, Sriurairatana S, Ruangpan L, Direkbusarakum S, Manopvisetcharean J, et al. Partial characterization of a novel bacteriophage of Vibrio harveyi isolated from shrimp culture ponds in Thailand. Virus Res. 2005;114(1-2):63-9.

6. Zhou K, Gui M, Li P, Xing S, Cui T, Peng Z. Effect of combined function of temperature and water activity on the growth of Vibrio harveyi. Braz J Microbiol. 2012;43(4):1365-75

7. Bankevich A, Nurk S, Antipov D, Gurevich AA, Dvorkin M, Kulikov AS, et al. SPAdes: a new genome assembly algorithm and its applications to singlecell sequencing. J Comput Biol. 2012;19(5):455-77.

8. Yoon SH, Ha SM, Kwon S, Lim J, Kim Y, Seo H, et al. Introducing EzBioCloud: a taxonomically united database of $16 \mathrm{~S}$ rRNA gene sequences and wholegenome assemblies. Int J Syst Evol Microbiol. 2017;67(5):1613-7.

9. Aziz RK, Bartels D, Best AA, DeJongh M, Disz T, Edwards RA, et al. The RAST server: rapid annotations using subsystems technology. BMC Genomics. 2008:9:75.
10. Overbeek R, Olson R, Pusch GD, Olsen GJ, Davis JJ, Disz T, et al. The SEED and the rapid annotation of microbial genomes using subsystems technology (RAST). Nucleic Acids Res. 2014;42(Database issue):D206-14.

11. Chen L, Yang J, Yu J, Yao Z, Sun L, Shen Y, et al. VFDB: a reference database for bacterial virulence factors. Nucleic Acids Res. 2005;33(Database issue):D325-8.

12. Pavia AT, Bryan JA, Maher KL, Hester TR Jr, Farmer JJ 3rd. Vibrio carchariae infection after a shark bite. Ann Intern Med. 1989;111(1):85-6.

13. Wilkins S, Millar M, Hemsworth S, Johnson G, Warwick S, Pizer B. Vibrio harveyi sepsis in a child with cancer. Pediatr Blood Cancer. 2008;50(4):891-2.

14. Hundenborn J, Thurig S, Kommerell M, Haag H, Nolte O. Severe Wound Infection with Photobacterium damselae ssp. damselae and Vibrio harveyi, following a Laceration Injury in Marine Environment: A Case Report and Review of the Literature. Case Rep Med. 2013;2013:610632.

15. Akram A, Stevens RP, Konecny P. Photobacterium damselae and Vibrio harveyi hand infection from marine exposure. Med J Aust. 2015;203(5):224-5.e1.

16. Del Gigia-Aguirre L, Sanchez-Yebra-Romera W, Garcia-Munoz S, RodriguezMaresca M. First description of wound infection with Vibrio harveyi in Spain. New Microbes New Infect. 2017;19:15-6.

17. Austin $B$, Zhang XH. Vibrio harveyi: a significant pathogen of marine vertebrates and invertebrates. Lett Appl Microbiol. 2006;43(2):119-24.

18. Linkous DA, Oliver JD. Pathogenesis of Vibrio vulnificus. FEMS Microbiol Lett. 1999;174(2):207-14.

19. Baker-Austin C, Stockley L, Rangdale R, Martinez-Urtaza J. Environmental occurrence and clinical impact of Vibrio vulnificus and Vibrio parahaemolyticus: a European perspective. Environ Microbiol Rep. 2010;2(1):7-18.

20. Montanchez I, Ogayar E, Plagaro AH, Esteve-Codina A, Gomez-Garrido J, Orruno $\mathrm{M}$, et al. Analysis of Vibrio harveyi adaptation in sea water microcosms at elevated temperature provides insights into the putative mechanisms of its persistence and spread in the time of global warming. Sci Rep. 2019;9(1):289.

21. Strom MS, Paranjpye RN. Epidemiology and pathogenesis of Vibrio vulnificus. Microbes Infect. 2000;2(2):177-88.

22. Le Roux F, Wegner KM, Baker-Austin C, Vezzulli L, Osorio CR, Amaro C, et al. The emergence of Vibrio pathogens in Europe: ecology, evolution, and pathogenesis (Paris, 11-12th march 2015). Front Microbiol. 2015;6:830.

23. Shaltout M, Omstedt A. Recent sea surface tempera- ture trends and future scenarios for the Mediterranean Sea. Oceanologia. 2014;56(3):411-43.

24. Bindoff NL, Stott PA, AchutaRao KM, Allen MR, Gillett N, Gutzler D, et al. Detection and Attribution of Climate Change: from Global to Regional. In: Intergovernmental Panel on Climate C, editor. Climate Change 2013 - The Physical Science Basis: Working Group I Contribution to the Fifth Assessment Report of the Intergovernmental Panel on Climate Change. Cambridge: Cambridge University Press; 2014. p. 867-952.

25. Shaltout $M$, Omstedt A. Recent sea surface temperature trends and future scenarios for the Mediterranean Sea. Oceanologia. 2014;56(3):411-43.

26. Semenza JC, Trinanes J, Lohr W, Sudre B, Lofdahl M, Martinez-Urtaza J, et al. Environmental suitability of Vibrio infections in a warming climate: an early warning system. Environ Health Perspect. 2017;125(10):107004.

27. Baker-Austin C, Trinanes JA, Salmenlinna S, Lofdahl M, Siitonen A, Taylor NG, et al. Heat wave-associated Vibriosis, Sweden and Finland, 2014. Emerg Infect Dis. 2016;22(7):1216-20.

28. Baker-Austin C, Trinanes J, Gonzalez-Escalona N, Martinez-Urtaza J. Noncholera Vibrios: the microbial barometer of climate change. Trends Microbiol. 2017;25(1):76-84.

29. Baker-Austin C, Trinanes JA, Taylor NGH, Hartnell R, Siitonen A, MartinezUrtaza J. Emerging Vibrio risk at high latitudes in response to ocean warming. Nat Clim Chang. 2012;3:73.

30. Muhling BA, Jacobs J, Stock CA, Gaitan CF, Saba VS. Projections of the future occurrence, distribution, and seasonality of three Vibrio species in the Chesapeake Bay under a high-emission climate change scenario. GeoHealth. 2017;1(1):278-96.

31. Parveen S, Hettiarachchi KA, Bowers JC, Jones JL, Tamplin ML, McKay R, et al. Seasonal distribution of total and pathogenic Vibrio parahaemolyticus in Chesapeake Bay oysters and waters. Int J Food Microbiol. 2008;128(2):354-61.

32. Jacobs JM, Rhodes M, Brown CW, Hood RR, Leight A, Long W, et al. Modeling and forecasting the distribution of Vibrio vulnificus in Chesapeake Bay. J Appl Microbiol. 2014;117(5):1312-27.

33. Areechon N, Koydon $\mathrm{S}$, Kitancharoen N. Effect of salinity and temperature on the viability of Vibrio harveyi. Kasetsart J. 1993;27(1):67-73.

34. Vezzulli L, Previati M, Pruzzo C, Marchese A, Bourne DG, Cerrano C. Vibrio infections triggering mass mortality events in a warming Mediterranean Sea. Environ Microbiol. 2010;12(7):2007-19. 
35. Heng SP, Letchumanan V, Deng CY, Ab Mutalib NS, Khan TM, Chuah LH et al. Vibrio vulnificus: an environmental and clinical burden. Front Microbiol. 2017;8:997.

36. Lee LH, Ab Mutalib NS, Law JW, Wong SH, Letchumanan V. Discovery on antibiotic resistance patterns of Vibrio parahaemolyticus in Selangor reveals Carbapenemase producing Vibrio parahaemolyticus in marine and freshwater fish. Front Microbiol. 2018;9:2513.

37. Bier N, Schwartz K, Guerra B, Strauch E. Survey on antimicrobial resistance patterns in Vibrio vulnificus and Vibrio cholerae non-01/non-0139 in Germany reveals carbapenemase-producing Vibrio cholerae in coastal waters. Front Microbiol. 2015;6:1179.

38. Baker-Austin C, McArthur JV, Lindell AH, Wright MS, Tuckfield RC, Gooch J, et al. Multi-site analysis reveals widespread antibiotic resistance in the marine pathogen Vibrio vulnificus. Microb Ecol. 2009;57(1):151-9.

\section{Publisher's Note}

Springer Nature remains neutral with regard to jurisdictional claims in published maps and institutional affiliations.

Ready to submit your research? Choose BMC and benefit from:

- fast, convenient online submission

- thorough peer review by experienced researchers in your field

- rapid publication on acceptance

- support for research data, including large and complex data types

- gold Open Access which fosters wider collaboration and increased citations

- maximum visibility for your research: over $100 \mathrm{M}$ website views per year

At BMC, research is always in progress.

Learn more biomedcentral.com/submissions 